\title{
The Virtualisation of Digital Photography
}

\section{La virtualización de la fotografía digital}

\author{
Jonathan Woodrow \\ Dept. of Human Sciences \\ Loughborough University \\ Loughborough \\ Leicestershire, U.K. \\ LE 11 3TU
}

\section{J.D.Woodrow@lboro.ac.uk}

\section{Resumen}

¿Cómo los humanos se relacionan con su tecnología? No se trata de una cuestión nueva, y muchos han lidiado con ella. Lo que queremos hacer aquí es hacerla visible mediante otro vocabulario, el virtual. Desenvolveremos este vocabulario reconfigurando los movimientos tradicionales que empiezan con categorías distintas para las cosas humanas y las cosas técnicas y buscan explicar una categoría en términos de las actividades de la otra. Mediante la Teoría del Actor-Red (ANT) optaremos por la Allegoresis como otro registro o vocabulario que hace visible tanto a la tecnología como a la gente. A partir de la obra reciente de Latour encontraremos nuestro camino hacia Walter Benjamin y su asunción de la Monadología de Leibniz como una vía de comprensión del modo simbólico Kantiano en términos históricos. Benjamin pide una explicación de la estabilidad del cambio histórico y la reinterpretación. La relación entre movimiento y momentos es lo que queremos describir al hablar de la relación entre lo virtual y lo actual. Además, es este vocabulario el que nos ayuda a entender o hacer visible la reescritura constante por la que pasa cualquier tecnología, configurada y reconfigurada del mismo modo que los humanos y no-humanos están colocados en formas históricamente contingentes.

Vamos entonces a interpretar lo virtual o llegar a él intentando fijarnos en los acuerdos de la gente y la tecnología en un club fotográfico donde los miembros están empezando a utilizar las tecnologías digitales.

Palabras Clave: Tecnología, Teoría Actor-Red (ANT), Virtualización, Fotografía Digital.

\begin{abstract}
How do humans relate to their technology? This is not a new question, many have struggled with it. What we want to do here is to make it visible through another vocabulary, the virtual. We are going to unpack this vocabulary by reconfiguring the traditional moves that start with distinct categories of human things and technical things and seek to explain one category in terms of the activities of the other. Through the Actor Network Theory (ANT) we will opt for Allegoresis as another register or vocabulary that makes technology and people visible. Through Latours's recent work we find our way to Walter Benjamin and his take on Leibniz's Monadology as a way of understanding the Kantian symbolic mode in historical terms. Benjamin asks for an account of stability from historical change and reinterpretation. The relationship between movement and moments is what we want to describe as that between the virtual and the actual. Moreover, it is this vocabulary that helps us understand or make visible the constant rewriting that any technology goes through as it is configured and reconfigured as humans and non-humans are arranged in historically contingent ways.
\end{abstract}

We are then going to play out the virtual or arrive at it as we look to notice the arrangements of people and technology in a photographic club where members are beginning to use digital technologies.

Keywords: Technology, Actor Network Theory (ANT), Virtualisation, Digital Photograpy. 


\section{Obvious Questions}

A set of obvious questions present themselves when thinking about technology and people: who is using it?, what are they using it for?, where and when do they use it? In addition, which bits of technology are they using? Directed at our digital hobbyists all these questions seek to understand how the bits of digital technology enter the home of human practice. This type of research agenda assumes a categorical distinction between human activity and technology. Here is an example; Hamill (2000) starts with this categorical distinction and asks how new technologies get into the home. These questions are sorted out in terms of some economic considerations. She believes that:

"Economic principles should be treated as fundamental to the design process [...] the demand of new gadgets in the home will be determined by the same general factors as the demand far any other item".

The key principle that informs the set of variables that Hamill wants new technologies to appear in is utility. She says:

"The economic theory of consumer behaviour is based on the assumption that households want to maximise their utility subject to a budget constraint'.

Utility usually means welfare, budget constraints refers to income and the pricing of goods but also to limits on time. Technological uptake is determined by its ability to satisfy welfare issues within the limits of income and available time. Hamill concludes that new technologies are taken up in the first instance by the wealthy, that using up time dampens demand for a new technology, and that people find out about technologies through positive feed back about the technology from others.

Hamill invokes economic variables to organise successful and unsuccessful technologies. Moreover, according to Hamill from the register of economics, we can design successful technologies. From the start, humans have problems set out in economic terms and technologies offer solutions from which we need to discern successful from unsuccessful solutions. What constitutes a good technology is not in the technology but resides in another register or economy of explanation. Economics has to do with distinctly human activities and attributes, demographics, demand, desires and tastes. As such the coordinates of what is good technologically are plotted out in terms of Hamill's societal variables as distinct from the terms and activities of a world of technology. The former is imposed onto the later to organise it. Society or economics sorts out what we understand of technology. The co-ordinates of technology as a solution are set out by the kind of problematisation that is secured in the economy of explanation that is the economic register.

Questioning people and technology in these terms sets the research process of making phenomena visible in terms of two categories of activity already set out; the human and the technical. The usual way to sort out technology and people analytically is to start with the assumption that they should be treated as separate territories of activity. Questioning concerning technology is concerned with issues around the entry of one camp into the other and interactions or directions of influence between them. We can now go off and start counting technologies and recording how they get into the home. 


\section{Advertising Worlds}

Technology is a problem for us in the home. From what constitutes the right kit to the uses technology is put to, to whether or not we need it at all. If we should be asking about the nature of the passage of technology into the home then adverts present no problem for our analysis. They must facilitate the passage of technology into the home and help us spot the gap in our homes that the technology is supposed to fill. This form of explanation reduces adverts to notification of instrumentality or the latest solution.

Is this adequate? There is no end of solutions suggested by manufactures. Sony recently ran an advertising campaign for one of its digital cameras in which a woman starts out from home on her way to a club for the evening. From her home and all the way to the club she takes photographs with her digital camera of key locations and landmarks. At the club, she sees a guy we can assume she quite likes and drops the camera that has a LCD screen for viewing images contained in it into his coat pocket. Then she leaves. The man takes the camera and cycles back through the images to find his way back to her home. What are we being sold? Not only a camera but also a new use for it embedded in nightclub behaviour. The world in the advert constructs a space where it makes sense to drop a piece of expensive equipment into a stranger's pocket safe in the knowledge that he would know what to do with it. Where cameras have cultural currency as navigation tools and images are disposable directional notes. Where "social" behaviours secure the return of your technology by constructing social channels for it to move along. Is this technology for technologies sake, where Sony have to invent a use perhaps to sell us the idea that technologies like this are open to inventive activity?

Kodak marketed their camera differently majoring on the capture and "off loading" facilities when used in conjunction with a PC. No particular image practice is suggested but other technology that is referred to afford different economies of use. The off loading dock connected into a PC allows images and texts to be combined; it also makes e-mail facilities available:

"Place your DX3500 camera in its dock, press the button, and you're ready to print and e-mail with ease. You'll never miss a picture-taking opportunity since your camera batteries are recharged every time you rest the camera in the Dock."

Are these ways of easing the passage between camps? Is it enough to argue that these adverts tell people about how technologies in terms of means to an end. Is the digital camera really the dating technology we have been waiting for? Alternatively, is there something more complicated that we need to notice, e.g. technology and social activity mixed up into worlds? For instance, Sony present us with a scene and a use for the camera which would only be possible if dating behaviour were to be dramatically transformed, as would attitudes towards expensive technology and theft. In short, a whole world of practice, culture, technology and sites of activity have to be arranged in order for it to make sense to leave your digital camera behind. A world in which things need to be arranged to make sense.

This is what we want to describe, not advertising but arrangements of people, technology and practices that support and configure one another into worlds. The two adverts present two very different ideas on what a digital camera is for and what it consists of. Both these adverts see manufactures mixing up social practice and different configurations of technologies into different economies of activities. Thinking about how we might theorise and analytically approach these mixes 
and movements in what constitutes a technology and social activity presents a problem for us as researchers. We want to think about understanding the relationship between technology and people. ANT helps in our search for allegory.

The challenge as Callon (1986) puts it to us is to maintain a single register rather than switching between technical things and human things. This is what ANT writers have sought to do by collapsing the society/technology distinction. The single register is translation, a vocabulary as Law (1992) says that allows us to describe how people and objects become arranged into networks. Where the social no longer constitutes a purely human category of explanation and agency but rather a mixture of human and non-humans equally organising each other. He says:

"This, then, is the crucial analytical move made by actor-network writers: the suggestion that the social is nothing other than patterned networks of heterogeneous materials. This is a radical claim because it says that these networks are composed not only of people, but also of machines, animals, texts, money, and architectures any material that you care to mention. So the argument is that the stuff of the social isn't simply human".

The claim is that all is the product of networks of heterogeneous elements that once were divided in the old categorical settlement. It is not a claim that says all technology is now included or pushed further into the social categories. It is a claim that reconfigures the social as neither a human nor a purely technical category. As such the move is to dissolve categories into activity in a single register and vocabulary. Callon (1986) and Law (1992) amongst others seek:

"To explore the process that is often called translation which generates ordering effects such as devices, agents, institutions, or organisations. So translation is a verb which implies transformation and the possibility of equivalence, the possibility that one thing (for example, an actor) may stand for another (for instance a network)" (Law 1992).

The important move is to say that actors have no meaning or identity outside of their relations to other objects. There is no universal category that they belong to supply identity. Once arranged or performed then attribution of identity or cause is the last move (Latour 1986). In order to argue for a new register, we have to understand the duality of Hamill's register.

\section{Allegory and Symbolic unity}

Society in Hamill's explanation occurs twice, first as society and secondly in the realm of technology. Technologies become examples, symbols, or signifiers of society's activity and attributes. Society becomes the signified. Hamill hopes to discern truths about the category of society or economics by capturing its appearance in the realm of signifiers that technology is.

Once we have chosen our signifiers our job is to make sure of their validity: do patterns of technological uptake as my measures (the signifiers) reflect or signify accurately the convolutions of a complex society (the signified)? Since signifiers are occasioned manifestations of the signified their content needs extracting from the "noise" that constitutes their form. Serres (1982) says mathematical abstract explanations require the cutting away of empirically difference in representations to point to an abstracted signified idea. The aim is to find the signifiers in amongst the noise of occasioned 
activity. Statistical analysis and the mathematical discernment of variables from noise or confounding variables represent an economy of managing the purity of signifiers. Part of the theory talk that goes on in the research is about arguing for the inclusion and exclusion of variables. Once theoretically underpinned they are converted into statistical operations. Indeed Hamill is keen to say that we need to consider all sorts of features of the form of technology including its time saving potential because one feature of society or economics' content is limited time and money before finding measures of these.

We want to call this the symbolic mode. In the same way the form solutions take is understood to represent the content of the problem. Technological solutions contain the problems they solve. They let us in on why they are there because the problem constructs the form of the solutions. The logical unity of these formulas of explanation comes because the structure of solutions is sorted out and logically represents the shape of the problem. Solutions are understood in terms of realisation.

Logical unity is a core notion in Kant's view of the symbolic mode. Bell (1997) explains the Kantian notion of the symbol. Kant makes a distinction between two forms of representation: the symbolic and the schematical. The schematical mode, says Bell, represents concepts to us by demonstration. The demonstrative object stands as an analogue to the concept having no meaning on its own only by virtue of its alignment with the concept as a vehicle. There is a difference between content and form in the schematical or allegorical mode. The demonstrating object transports the content of the concept but through the object's form, this is translation: displacement of content through transformation of form. The symbolic form however sees a unity of content and form. Bell quotes Kant: "The symbolic form presents us with something for which no sensory representation would be appropriate, it gives us access through the particular to the general "idea'". As such the symbol is at the same time the idea manifested and tangible in its form and content just as the solution logically represents the problem. We see this unity between symbol and signified in the above explanations and research methods. We look for examples of the thing we can't get accesses to through our measures, society variables or society in technology which are at the same time form and content examples of the wider idea. Technology represents society as its form is derived from it.

\section{Historical Form}

Hetherington and Law give us a useful insight into the nature of this of symbolic unity. If concepts are mediated by another's form in allegorical representation then symbolic representational unity claims unmediated communication. A unity between objects and their signs between the content and the form of communication between seeing the object (the content) and saying (the form) the object, between measures (form) and phenomena (content). However, unity is illusionary because the form or sign points beyond itself.

Latour (1999) describes the symbolic mode of unmediated communication when he argues that the correspondence that modernity assumes between speaking and seeing requires us to except an unmediated leap across the gap between signified and signifier. However, Latour argues that "The cat is on the mat", as a sentence is not the cat sat on the mat in front of the speaker. It is a complex series of culturally and historically contingent displacements and transformations through which words come to stand for things. Cat is a transformation and displacement of the object. The object as content has no unity with the form of its vehicle of displacement, which transforms it, i.e. the word cat. Since cat is 
an arrangement of the world, it makes the object visible through historically contingent alignments. This is the Modern epistme for Latour. We are asked to buy into the notion that content dictates form and ignore the fact that form is actually historically contingent and is always a transformation and displacement of content. Latour gives form or technology a voice as it becomes part of what is arranged to make things visible.

Hetherington and Law, in a draft paper called "Allegory and interference: Representation in sociology", agree with Latour and say that the "Modern [epistemological] project seeks to let the eye speak directly but in allegory the relation is less direct". In the system of allegory, we have seen that things stand for things that are not present. As Hetherington and Law say, "allegory relies on similitude, on a chain of signifiers where there is no direct correspondence between matching signifier and signified. Instead, there is a mobile play of connections between them." What the allegorical buys us is more than a vision of the space between signified and signifier as if tying a moving sign to a fixed signifier. It allows us to see that what was once read as the signifier or form is now read as an allegorical achievement and it becomes the mode of constructing or locating or making visible the signified. The content or signified is constituted as it is given form that is as it is translated into a particular context.

Latour (1999) explains through his example of the pedocomparator that contains samples of soil arranged in terms of depth and area, etc. The soil samples in the pedocomparator are not explained by the forest floor, which they come to represent, rather, the forest floor is made visible by its translation. The pedocombarator is a set of its transformations and displacements where by the forest

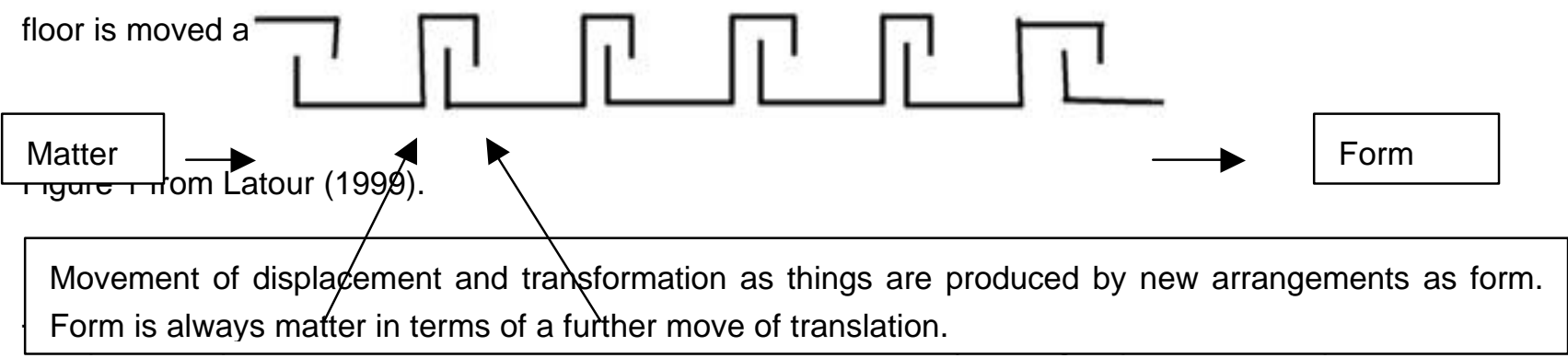

articulate the forest in terms of a particular economy of inquiry and issues to be addresses. Figure 1 from Latour shows the move of displacements and transformations. Each transformation is a reconfiguration of an object in terms of a new set of practices that give it form. Since all form is historical contingent, it is always open to further transformations and displacements.

The diagram describes the existence of an object, phenomena, society of microbes in terms of their history or movement through transformations and displacements. Historicity is essential for Latour. He asks: "did ferments exist before Pasteur made them up?". There is no avoiding the answer: "No, they did not exist before he came along". We might ask: did society exist before Hamill describes or makes up its features in terms of what technology is successful and in demand? We would have to answer: no. We would have problems with these assertions if we observed the society/nature dichotomy and kept objects separate from subjects. As Latour argues in Pandora's hope (1999), this dichotomy forces us to read these assertions as if we mean that Hamill makes up or invents society:

"The subject-object dichotomy distributed activity and passivity in such a way that whatever was taken by one was lost to the other. If Pasteur makes up the microbes [with his lab equipment and measures], that is, invents them, then the microbes are passive. If the microbes lead Pasteur in his thinking then it is he who is the passive observer of their activity". 
So the assertion that Hamill (2000) makes up society is meant to suggest that her techniques of isolating variables do all the construction work, as opposed to the idea that her variables are passive measures that reflect and are constructed by society. Instead, as Latour argues:

"We have begun to understand, however, that the human-nonhumans does not involve a tug of war between two opposite forces. On the contrary, the more activity there is from one, the more activity there is from the other. The more Pasteur works in his laboratory, the more autonomous his ferment becomes".

As the microbes encounter Pasteur they are transformed in terms of Pasteur and his techniques of scientific enquiry at the same time, those techniques and scientific practices are transformed to perform the microbes as microbes. Techniques are altered and experiments designed to isolate or describe characteristics of the microbes. The characteristics are worked up in terms of equipment and practice and are attributed to the microbes. As more and more characteristics are described and performed, the microbes move from simple capacities. From activity to objecthood. Leibniz's discourse on metaphysics (1686) contains a description of a similar process of becoming an individual substance which, later in his philosophy he refers to in terms of the Monadology - the construction of the world image: "it is certainly true that when several predicates are attributed to the same subject, and this subject is not attributed to any other, it is called an individual substance". The process of discerning variables and measuring them in terms of technological uptake is a process of attributing predicates to society, moving it towards the status of a complete and individual notion or substance.

Transformation and displacement puts end to a unity of explanation that starts with an individual notion appearing in and organising another register rendering that register mere statements about the referent. And it opts for a different sort of unity, one of becoming or performance rather than that built around the active in the passive. As such, the signified loses its fixed position as source of explanation and ordering because it is constituted through the movement and alignment of objects into relationships that are only then seen as possessing logical unity after they are arranged.

The symbolic required fixing a signified source. Fixing society required a moveable dislocated technology. Technology becomes a mass of equivalence waiting in front of an independent society to intervene and organise it. Fixing technology similarly requires the meltdown of society into a mass of equivalence. Latour (1999) says:

"but where does this fixity come from? Only from the settlement that anchors the object of reference as one extremity facing the statement on the other side across a yawning gap. Ferments exist, however, does not qualify one of the poles [...] but the whole series of transformation that make up the reference".

The allegorical requires the dislocation of everything into equivalence into movement. The task then is to understand how a symbolic explanation becomes fixed and stable rather than assuming stability for all time to do this we have to understand mass and movement. The space that the allegorical makes visible is this zone of movement. It is this space that we want to describe as the virtual. The task that Benjamin set to was describing this zone or space as mass that he saw as a result of modern technologies of reproduction. We will now turn to Benjamin to understand this mass as enabling limit that we want to call the virtual. 


\section{Walter Benjamin's Allegorical Unity}

Benjamin was concerned with how the unity of the symbolic was achieved. Benjamin's project can be understood as reclaiming the allegorical mode seen as inferior or as a failed symbol and reconfiguring the symbolic as allegorical in nature. The analytical move is reversed. The usual method starts with stable located sources and describes or explains change in form of another category, e.g. technology. Here with Benjamin we start with movement and attempt to account for stability. What needs describing is fixity from movement, this is the actual from the virtual.

If the Kantian notion of the symbolic is about a unity of form and content as we have seen, then communication occurs immediately because the idea is in and is the symbol. Bell (1997) says that as opposed to the immediacy of the symbol, allegory finds its expression in "the flow of time". The difference is that allegorical relations as we have seen are historically contingent. While the symbolic mode's immediacy is taken to be outside of time and universal because, traditionally, understanding of the symbolic mode excludes the work that has to go on in aligning or folding up and securing the symbolic relationship from the analysis. However, as Bell says, since the symbol attempts to signify something beyond its self it lets in time. Its unity is illusionary. The appearance of unity between society in technology requires us to buy into an ahistorical view of the unity of form and content.

Benjamin (1977) makes the same distinction but does so by locating the symbolic within time:

"The distinction between the two modes is therefore to be sought in the momentariness which allegory lacks [...] there [In the symbol] we have momentary totality, here [in allegory] we have progression in a series of moments".

Here Benjamin recasts the universal symbolic unity as a temporally historically contingent totality reducing correspondence between sign and signified to Latours transformations and displacements. While allegory is about relations through time, this connects the symbolic mode with the allegorical. Since the symbolic constitutes one moment, it is a single moment in allegorical progression. As such the allegorical needs the series of symbolic moments and as we have seen the symbolic, its self has to be arranged from objects relating allegorically. The greater then for Benjamin is allegory since it is allegory that is the mode of symbolic constitution. Benjamin's project as Hetherington and Law point out is to understand how this relationship works, that is how unity is temporally achieved. They say "Benjamin seeks to extract from the material flux [series of moments] of the world, an eternal image, a monad [a single moment] that comes to represent the world as a whole". It is this relationship that we want to describe as that between the actual and the virtual. The virtual describes the series of moments and the actual describes the moment or the monad. In order to understand this relationship, we have to understand first the moment or symbolic unity as embedded in tradition, that this is about a process of recording arrangements of the world.

We find all this in Benjamin's descriptions of Aura and technologies of reproduction. Aura for Benjamin is a recasting of the features of unity and momentariness of the symbolic mode in terms of the allegorical mode. In "The work of art in the age of mechanical reproduction" (1969) Benjamin argues for the dissolution of the aura of the work of art at the hands of reproductive technologies and mass movement. It is in the contrast between mass production and uniqueness that we find the constitution of aura through the allegoric mode. What is the aura (or moment) of a piece of work? It is that which a copy made through reproductive technologies lacks uniqueness in time and space. He says: 
"Even the most perfect reproduction of a work of art is lacking in one element: its presence in time and space, its unique existence at the place where it happens to be".

Just as Benjamin describes the symbol as rooted in the moment, so the originality or uniqueness of an object is made through its spacio-temporal location and it is this that gives an object its authenticity.

"The authenticity of a thing is the essence of all that is transmissible from its beginning, ranging from its substantive duration to its testimony to the history which it has experienced. Since the historical testimony rests on the authenticity, the former, too, is jeopardised by reproduction when substantive duration ceases to matter."

The uniqueness of an object comes from its embeddedness in history or tradition. In the reproduced object, we find a parallel with the Kantian notion of the timeless symbol. Unlike the Kantian symbol which is understood to be outside of time where its duration "ceases to matter" Benjamin's aura is a product of its duration in time, that is, a product of all its history so far. Its momentariness is its testimony to its historical constitution. The momentariness of the symbol is a snap shot of its current temporal location which is always unfolding and which is always a product of its past. Benjamin describes the historicity of the object in allegorical terms when he says: "the uniqueness of a work of art is inseparable from its being embedded in the fabric of tradition".

\begin{abstract}
"The technique of reproduction detaches the reproduced object from the domain of tradition. By making many reproductions, it substitutes a plurality of copies for a unique existence. Moreover, by permitting the reproduction to meet the beholder or listener in his own particular situation, it reactivates the object reproduced. These two processes lead to a tremendous shattering which is the obverse of the contemporary crisis and renewal of mankind. Both processes are intimately connected with the contemporary mass movements."
\end{abstract}

If aura is dependent on locating in time and space then reproduction technologies dislocate the aura in two moves. Firstly, Benjamin describes how they overcome spatial location by conquering distance as copies can go where originals cannot, into books and homes. Secondly, they can go to many please at the same time there by destroying the temporal location of the original, lifting it from tradition. All this is achieved by the replacement of the unique with a "plurality of copies" and is part of "contemporary mass movements".

Weber (1996) helps us understand how mass and movements are essential to understanding the move from the unique to plurality. He translates "By making many reproductions, it substitutes a plurality of copies for a unique existence" as "by multiplying the reproduction [of the artwork, the technique of reproduction] replaces its unique occurrence for one that is massive or mass-like". The move is not simply from art taking its place traditionally in the "here and now" to a collection or a plurality. The move is from the former to a mass. Mass is tied to the technique of reproduction of not simply a result. Weber explains that we can discern from Benjamin's writings that mass movements are the corollary of the detachment from tradition that Benjamin writes of above as the decline of the aura. The important moves are temporal movements from the moment and spatial Weber says "for the aura relates to mass not just as uniqueness does to multiplicity but also in spatial terms, as a fixed location does to one that is caught up in an incessant and complex movement". The aura of art for Benjamin takes place spatially and temporally. This is how it is embedded. Mass movement is about 
the decline of aura because it dislocates in time and space opting for movement. We can think about the virtual as the move towards mass movement and the actual as the move toward taking place. As we have seen above, the actual is about fixing time and as such it requires the movement of time and space. It turns out through Benjamin that these moves are more closely related because the movement of time and space (the virtual) is the enabling limit of actualisation. All is allegorical; the move to mass movement in no way changes our register; in fact it points to the redemption of aura or symbolic unity. This is what Weber goes on to describe. Returning to Benjamin's other statement on the aura of natural objects Weber casts it in terms of setting a scene or having the aura take place:

"On a summer afternoon, resting, to follow a chain of mountain's on the horizon or a branch casting its shadow on the person resting - that is what it means to breathe in the aura of these mountain's, of this branch".

Aura here makes sense in front of and as separated from a viewing subject. As such part of the construction of aura is the securing of a point to be distanced from, this secures the subject. Weber concludes that the taking place of the aura is a process of taking leave from a point in constructing that point. It achieves the appearance of locatedness and distance by a process of self-detachment.

"The aura would be able to return in the age of technical reproducibility because, as the appearance or apparition of an irreducible separation, it was never uniquely its self but always constituted in a process of self detachment: detachment from the self as demarcation of the self."

If the aura were uniquely itself then we would view technologies of reproduction as something that happens to the aura from outside. Here however, its own process of demise that involves technology constitutes the aura. The aura is technical and social, human and nonhumans in a process of fixing and unfixing. It is this process that we need to understand to grasp the relations between virtual, as enabling limit, and actual, as arranging a world.

\section{Tradition and Movement as an Enabling Limit}

The tradition that aura is embedded into isn't fixed but it is always unfolding:

"This tradition itself is thoroughly alive and extremely changeable. An ancient statue of Venus, for example, stood in a different traditional context with the Greek's, who made it an object of veneration, than with the clerics of the middle ages, who viewed it as an ominous idol. Both of them, however, were equally confronted with its uniqueness, that is, its aura".

If the aura or uniqueness is inseparable from its historical context then it does not come from a particular arrangement of meaning but from the fact that it is secured as a located object in terms of its context. Each tradition that it appears in rewrites as it maintains it as an object. Its history then is the accumulation of different rewritings, what it has been to different situations. Each rewriting secures it in contextual terms as an object that is rewritable here and now. The result is that objects or aura locatedness are their own manner of progression through a series of moments or historical and cultural locations (see figure 2). Movement or virtualisation secures the object as a recording space through its constant reactualisation. We can think about actual as writing on to the virtual recording 
space. It is in this sense that the virtual is an enablina limit. Writina and rewritina is the process of self-

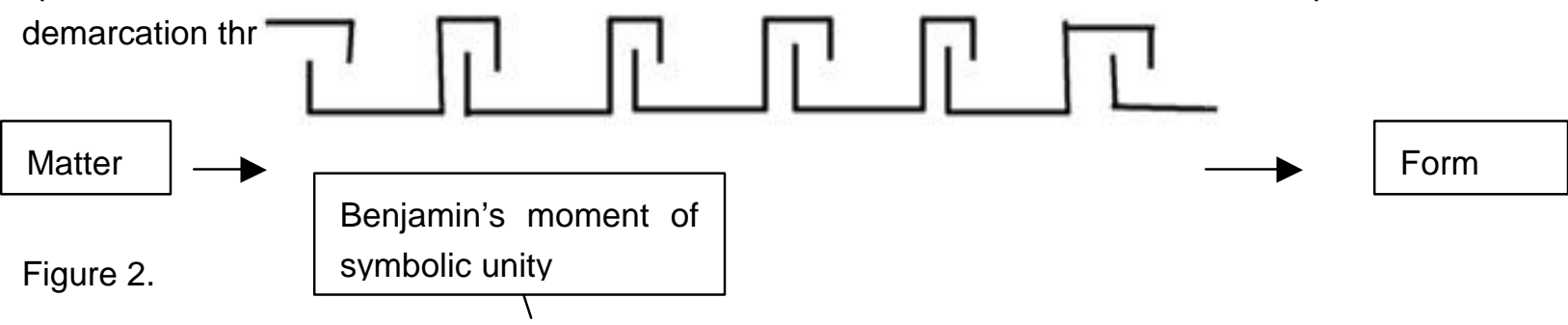

Benjamin's piece on collecting books (1969) further illustrates the constitution of aura as the accumulation of allegorical arrangements of meaning, as a space for writing and its links to symbolic unity as writing of the world. Benjamin says of the book and its collector: "the period, the region, the craftsmanship, the former ownership — for a true collector the whole background of an item adds up to the magic encyclopaedia whose quintessence is the fate of his object". Parker (1997) commenting on this quotation says it exemplifies Benjamin's tendency to see a grander narrative in the specific object. The grand narrative is more than the objects immediate history "but history itself as it spills out from history's most conservative vessel". In Benjamin, we find the idea that the work of tradition and history is about aligning the world to produce the aura of the object. The aura then as Hetherington and Law point out is akin to the Monad of Leibniz; they quote Benjamin: "the idea is a monad - that means briefly every idea contains the image of the world. The purpose of representation of the idea is nothing less than an abbreviated outline of this image of the world". It is the relationship between this history and the object that we find a parallel with symbolic unity. Parker explains that Benjamin quotes Proust on the relationship between these two, "the past is somewhere beyond the reach of the intellect and unmistakably present in some material object". Just as the signified is out of reach to the senses where the sign is not. The object is and stands for its own history, with the monad analogy we can go further and say the object's aura is an organised unity reflecting the history of a world since it is the point around which the world, past, present and future are arranged.

Serres (1968) says "The science of Conic sections shows clearly that there exists a single point from which an apparent disorder can be organised into harmony [...] For a given plurality, for a given disorder there only exists one point around which everything can be placed in order; this point exists and it is unique. From anywhere else disorder and indetermination remain. From then on, to know a plurality of things consists in discovering the point from which their disorder can be resolved, into a unique law of order". Benjamin's moments are monads that ordered the world. They are scenes in the sense of the Monadology rather than the Kantian scenography (see Latour 1999). The Aura is the point around which order is produced. It is the point that is written and secured as it orders.

The difficulty for the timeless symbol was in the leap between signified and signs, here the leap is mediated by the same allegorical logic that makes the world image. The collector in inheriting or writing his own recontextualises the book, makes it his own, owns it as the ancient statue of Venus was past on from tradition to tradition to be rewritten, so Benjamin took texts and translated them adding them to his collection. It is through constant recontextualisation and translation that unity is produced. That which is beyond the intellect (we now see as history) becomes united in the moment with the object as it is translated as the world is aligned to secure its aura in time and space. The effect of translation is the creation of a monad as Hetherington and Law point out:

"Through the monad [...] Benjamin sought to hold time still so that the materiality and spatiality of human history could be crystallised in a baroque image, often of a ruined 
past, that would shatter the illusion of progress and offer redemptive glimpses of hope for the future. For Benjamin, these distilled images are the vehicle for allegory".

The maintenance of unity is achieved through movement that is through a series of moments or translation. We can say that the actual is achieved through the virtual. It also throws the usual methods above into a new light. They are themselves world images, allegorical alignments of the world into monads that hold their own time up. Within the monad everything is explained symbolically, the world is sorted into accordance with either society or technology.

The move to actualisation then is a process of virtualisation. Unity is achieved through alignment that is always a process of rewriting the whole world enabled by its blankness or recordable surface secured by virtualisation. The question for us then in terms of technology is how is a technology written? This is not the same formulation as technology in society. As we have seen the allegorical rendering of the question drives us to look at the arrangements of social and technical elements in arranged together, technology no longer finds its essence in itself as separate from this process of recording and arranging. The question becomes how do we secure a technology out of the mass movement of humans and nonhumans. Since this question concerns essence of technology as actualised or brought forth then the obvious place to turn to is Heidegger's "the question concerning technology." Heidegger is an even more appropriate source to find some analytical direction since Heidegger's four modes of causation that constitute the move of bringing forth or setting in place (poises) can be thought of as describing the move from the virtual to the actual. This is no surprise because Heidegger was concerned with modern technologies and with collapsing dichotomies thus describing mass and movement as Benjamin. More importantly, Heidegger is concerned with bringing forth as an act of bringing things into accordance, which is about the allegorical mode.

\section{Heidegger and Poises}

Hamill looked for the essence of technology in terms of means to ends, what does it do for us. This instrumental definition is described in terms of ontical questioning in "the question concerning technology." That is, questioning in terms of how things match or accord with what we have already set up, i.e. the always already. The always already is that which is arranged or set in place and is taken as original, it provides a yard stick for everything else, just as society explains technology. Heidegger arrives at the ontological question via a trip through the notion of causality where he reconfigures causation as responsibility. Briefly Heidegger points out that causality is tied up with the instrumental definition of technology. Technology is the means by which an end is brought about. Heidegger presents us with four modes of causation and illustrates them with their co responsibility for the production of a chalice.

For centuries philosophy has taught that there are four causes: (1) the causa materialis, the material, the matter out of which, for example, a chalice is made; (2) the causa formalis, the form, the shape into which the material enters; (3) the causa finalis, the end, for example, the sacrificial rite in relation to which the required chalice is determined as to its form and matter; (4) the causa efficiens, which brings about the effect that is the finished, actual chalice, in this instance, the silversmith.

Heidegger's project here is to uncover the essence of technology by tracing its instrumental representation back to four-fold causality and recover something of Greek thought. He argues that today we are more accustomed to representing causality in terms of the causa efficiens, as that which 
brings about effects. He stresses that bringing about here in common understanding is understood in terms of obtaining effects. The problem comes with the understanding of causa, which means to bring about, to effect, and it belongs to the Romans and to our understanding. Heidegger says that the Greek from which we inherit the four causes has nothing to do with bringing about and effecting. The Greeks used aition, that to which something is indebted. Heidegger argues then that the four causes are interrelated by their co-responsibility for something else. So the chalice is indebted to the matter, the silver from which it is fashioned but at the same time it is indebted to "chalicness" the form into which the silver enters which is co-responsible with the silver for the chalice. Thirdly the chalice is indebted to "that which in advance confines the chalice within the realm of consecration and bestowal". It is through this that "the chalice is circumscribed as a sacrificial vessel". For that which circumscribes or gives bounds, Heidegger uses the Greek telos, in the sense that bounds don't stop a thing but instead set a thing off within them on its way to what it will be after production. Telos, usually translated as "aim" or "purpose" doesn't capture this aspect of responsibility. The chalice then is indebted to the practice of sacrificial rites as the telos that is responsible for the complete circumscription of what silver (matter) and chalicness (form) together present as a sacrificial vessel. All three then are responsible. The fourth responsibility is that of the silversmith who usually figures as the causa eficiens, the cause of the effect that is the chalice. Heidegger argues that there is no place in Greek for the responsibility that the silversmith has. For Heidegger he is responsible for gathering together the three modes of responsibility and so he is co-responsible for bringing forward the chalice and setting it off into being, indebted for it's subsistence to the four-fold ways of being responsible.

Next, Heidegger makes the move to say that what unites these ways of being responsible is that they are modes of occasioning, that is, bringing forth into the here and now. In bringing forward the chalice as lying before us and lying ready, these modes of responsibility bring it into appearance, bring it into presence, or we might say, bringing a world into presence. In so doing they set it on its way to arriving at what it is says Heidegger. For Heidegger then, bringing forth is about occasioning or inducing to go forward into appearance - having a world take place.

\section{Having Digital Photography Take Place in a Photographic Society}

Turning to our digital evening now we can ask how does digital photography take place for individuals. We can analysis their projects in terms of Heidegger's four-fold reconfiguration of causation. We can look at which equipment they invoke in which practices to particular ends and how they organise themselves in the process of performing or revealing their alignments of activity and technology into monads - that is how they align, for a time, a version. The data was recorded at an evening of a photographic society where members presented some of their photos and talked about their projects.

\section{Some Examples}

This first extract comes from John's introduction:

$\mathrm{J}$ : [alls l've done is l've (.) brought (.) roughly a dozen prints (.) to show you ] (.) and they're what I've A: [general commotion] 
$\mathrm{J}$ : produced over the last fifteen months since l've had the computer (.) more by trial and error (.) but I've just bought one or two (.) just to give you some idea of what - some are (.) not so good as others (.) but (.) this one here (.) I produced this (.) and unfortunately (.) these coconuts (.) out in (.) where I took this (.) they chop all the outside off so they were white (.) so I attempted to colour them (.) but at the end of the day I thought (.) it's no good worth it (.) so (.) I printed another one but without the coconuts

\section{A: [laughing]}

$\mathrm{J}$ : and (.) put in the curb (.) as well (.) it takes a wee bit of time but not (.) not such a great deal of time (.) and most of my pictures have only got minor details (.) er I don't consider that to be anything drastic cause you could do that in the dark room anyway (.) so whe- when people get worried about digital imaging you got to remember that (.) where the bloke in the cupboard who's not with us now unfortunately (.) he used to produce pictures (.) with five or six images (.) on one piece of paper (.) and we all thought it was fantastic (.) and nobody ever said (.) that wasn't a photograph

This first pair of images opens the way for John to introduce the level of alteration that he wants to argue is acceptable. From gathering together digital imaging and the darkroom as part of the heritage to the darkroom as cite of artistic production, John gathers practice and heritage around digital imaging, opening up a past, present and future for it digital and the user as artist.

John's comment "it's just a piece of art" removes the digital image from the photographic claim to reasonable truth and the concerns of representation into the realm of "truth autonomous" art where image stands on its own away from referent. It represents the final category into which all digital and photography is placed. Tracing the argument backwards, the "art" John refers to is the hypothetical montage image produced by the bloke in the darkroom that no one would deny was a photograph and a photographer. The darkroom, then, was always about pieces of art, about the collection of separate images to the cite of a single piece of paper creating the appearance of representation without there existing anything past the representation. The photograph was always a product of calculation, of organisation, gathering and performing rather than reflection of external reality.

Contrast this with the Billy's offering that came after John's presentation. Here Billy introduces her work.

B: all of these photographs I'm going to show you are basic (.) l've done no moving and haven't been able to take anything out or put anything in (.) so all I've done (.) is (.) I've taken photographs for a long time: (.) which (.) I go out and sketch and then I take photographs (.) if I haven't had time to do a sketch (.) I'll do photographs (.) and (.) I can bring them home and use them (.) not copy them I use them (.) a::nd l've got the memories of (.) where l've bee::n I bring back with me and as soon as I look at a photograph I'm back there (.) so:: (.) this is why I take photographs.

B: these are all (.) the photograph was put into the scanner (.) if they'::re (.) seven by five l've (.) erm enlarge them (.) erm (.) hundred and fifty percent (.) if they're six by four (.) l've enlarged them (.) two hundred percent which gives me A4 (.) or as near to A4 as I can get (.) erm (.) I put them into the scanner and pre- and with the mouse I can press the button and (.) and it (.) scans it fo::r me (.) and then if I feel that I want to lighten the highlights or darken the highlights (.) all I do l've got (.) I put on erm (.) oh (I can't think what they're called) I'm I'm no good at all these things I don't remember names but (.) I can get it (.) I can make the highlights lighter or darker (.) I can make the shadows lighter or darker (.) and I can make the (.) midtones lighter or darker (.) I rarely (.) do $\mathrm{m}$ (.) any mucking about 
like that because (.) I just- depending on the paper (.) I've experimented with various types of paper, just ordinary plain (.) erm (.) paper, thin paper with thicker ca::rd (.) and then I had a cheapy (.) erm (.) paper (.) gloss (.) gloss paper but it was a bit sort of rough to feel (.) I forget the name of it (.) and then I went to:: (.) erm (.) (illford) which I get fro::m (.)jessops (.) because I find they're as cheap as any body (.) and I got some illford paper from the::m (.) and (.) they'd reduced the price (.) plus the fact being the a student $($.$) in ceramics ($.$) at ($.$) (townhill) college you get ten percent off=$

$\mathrm{A}:=\mathrm{hhhh} .=$

$\mathrm{B}:=$ So that takes quite a bit off because (.) it is expensive (.) I find the paper (.) well the way I use it it is expensive because I go through reams of it (.) plus the fa::ct (.) the printing er the the ca:::tridges (.) are expensive (.) I'm on my about my fo::rth lot now this is is just before Christmas (.) but (.) nevertheless it's because I'm experimenting all the time so I won't waste anymore time so (.) l'll show you now what l've been doing if you can see (.) now [coughs] (.) this was the very fi:rst one I did (.) I don't know whether you can see them but if they're not big enough (.) l'll pass them round
U: I can see them
B. erm that (.) is the light on at all
U. yeh that's better
B: that's crackley woods
U: po leave the light on max
A. general commotion
U: it's just when [I lean back]

erm that's crackley woods (.) now that just went straight into the scan- into (.) the printer into the scanner and went straight through (.) erm that o::ne I did the same thing (.) er I didn't do any adjusting but I did find (.) that on different paper (.) it wasn't as good (.) this is just erm (.) a note book paper that's a smooth one (.) and I found that - I find that's the best paper (.) for me to u::se er(.) so those are those two but if you- you can pass them round if you want to look

Billy stakes out her project as much in terms of what she does not do as she does in terms of what she does do. She has not moved anything about, added or taken anything away. Presented like this the image and its components that might be moved about are at the default position in a sense. Her reference to movement, etc., refers to John's presentation and other demonstrations of manipulation so Billy's comment is significant as a signpost of the distinctiveness of her project. We are told that the photos presented are from photos placed in the scanner; "now that just went straight into the scan, into the printer, into the scanner and went straight through". The key moments in the process are inputting and output. In the middle things might be enlarged or improved in terms of light contrast, but the key technology presented are input and output devises. Importantly the images have a readable existence previously to the process they start as photographs already. Output is recognisably equal to input. Billy's talk then is around printing issues, paper, size, expense, and the development of her abilities occurs through experimenting in these areas. The computer acts as an enhancing technology and actually is secondary to image as its facilitator. Contrast this with John's description of the darkroom practice of making montage, the image originates from there, the scene depicted never existed. For John the computer is primary, image is secondary. It comes out as a product. This 
following conversation between Billy and John brings the origins of image and the primacy of the computer and its environment into focus.

A: have you done all these from slides

$\mathrm{J}:$ all of these are from slides

B: well what do you do just put your slide in the scanner [or]

J: [use] that- (.) like D's got his minolta scanner here you put your slide in (.) you scan it through and a picture comes up just like that there

B: really

$\mathrm{J}$ : and then [you] work it from there

B: $\quad[a h]$

A: $\quad X X X X-$

U: see (.) if you do that you don't need a digital camera (.) after you just bought one

\section{A: [laughing]}

$\mathrm{J}$ : you see (.) the sl- actually slides are more difficult to get good pictures out of than negatives

B: yeh

$\mathrm{J}$ : because of the contrast range

A: well you don't put a negative in do you

$\mathrm{J}$ : yeh you can put negatives in yeh

B: really

J: yeh

B: oh

U: that was a negative

B: right

An audience member asks John about whether transparencies were used and John says they were. Billy squeezes what is clearly a revelation to her through her version of digital technology. She uses a flat bed scanner and asks if you place your transparency on that. John answers by introducing her to a different input devise, the Minolta scanner looks like a CPU tower with a small slot on the front. $\mathrm{He}$ explains that the slide goes in it and a picture comes up just like that there on the computer screen to one side of his presentation. Billy is surprised, it "really" demonstrates further the novelty of this to her. John continues with it and then you work it from there. Two things are important here, transparencies need other equipment to be read. Alone, they present difficulties, they are designed for injection into another set of technologies that make them appear. Onto this, John adds that you then work them from the screen. Unlike the flat bed scanner and photograph, John's images require the computer to come into view to be revealed. The photo on the flat bed scanner does not need to be entered into the 
economy of the computer and its environment to be read and have currency. John later goes further to suggest that actually it is better to start with the most fundamental stage in photographic processing, the negative as you can process it in a number of different ways. It becomes clear now that with this arrangement of technology negative, Minolta scanner, manipulation software that renders negative readable and finally printing it is only a short step to the darkroom analogy. Picture originate become are sent forth by manipulation in John's economy. Billy's practice then can be seen as quite different.

A third presentation offers a different conception of image again:

D: everything on the computer is working in red, green and blue and the combinations of the red, green and blue er from naught to two hundred and fifty-five in each of the cases so you can see on this one that er although the statue was absolutely pure white in the shadows you can see that we've got blue and green are very similar in value red (.) is lacking some what alright so in effect we're going towards a cyan type of colour".

Derek presents the pixelation of image as he describes the manipulations that can be done on individual pixels when image is reduced to red, green and blue values. The economy that makes images visible here is one of graphs charts and numbers.

The point to make is that all three as gatherings of practice, technology and people differ as economies with distinct centres of gravity. Image for Billy is raw material for painting, memory aid, and translation of scene that exists outside of the computer set-up which represents an extra option but which is nothing more that an economy of reproduction where input equals output. As a gatherer, she is an artist who brings together paper printing, ink painting, easels and invokes all manner of artistic material. Here purpose or the telos is reproduction, the form that digital photography takes is reproductive technology. For John, image originates as a product from the computer, output is different to input. Input is calculated, collaged and printed as something different. It is about darkroom practice what photography was always about. John invokes darkrooms and paper. His artist's status is as an arranger of montages. The form digital takes is in terms of the production of image. Our quick look at Derek's comments again demonstrate a different economy of activity, pixel based manipulation but manipulation of number and graph curve. Image is about mathematised. Digital is about calculation; we might call him a technician. In a sense, we can see the scaling up and down of digital technologies across these three. At its widest gathering, Billy has it as a facilitator, it's about image practice. Then comes John describing the origins of image in terms of picking images apart by their subject, people objects, and reducing photographs to layers. Then Derek scales it down further to mathematics and graph manipulation. Where is digital photography, is it in the mathematisation of image or the movement of objects and the creation of something new in the artistic tradition of the darkroom or is it the reproduction of images facilitating painting and aiding the sketching process? Is it photograph, scanner, printer, or negative, scanner manipulation, printer, or mathematics calculation? It is all of these and none of these. These are versions, organised worlds of form and tradition, which are brought forth and rewriten on to the space that is digital photography.

This is the essence of technology or technics, it is a mode of bringing forth. To understand how all the above are connected and equally writings of digital then we have to understand essence and poises or bring forth. 


\section{Weber, Heidegger and Wessen}

Weber (1996) explains that the word usually translated as essence is Wesen. He argues that essence is not what Heidegger was after in talking about the essence of technology. He say "technics [Weber's preferred translation of technology] [...] compels us to rethink the meaning of Wesen and no longer construe it in the sense either of genre or of essentia". Weber translates Wesen as goings-on as the German communicates a sense of staying in play rather than fixed in essence of possessing essence. This is important and it repeats our theme of movement rather than located identity. Going-on and staying in play invokes an unsteady unfolding over time rather than a fixed timeless existence.

Weber says "the goings-on of technics are on goings, not just in the sense of being long standing, staying in play, lasting, but in the more dynamic one of moving away from the idea of a pure and simple self-identity of technology. What goes on in and as technics, its Wesen, is not itself technical". We have seen this last point above. Technology goes on indebted not to distinct social and technical categories anticeding it. It is not an effect of society but it is indebted to humans and nonhumans, traditions and other technologies, social procedures all mixed together. Its essence or Wesen is in bringing forth or in the act of poises - that is the movement from concealment to unconcealment. Its Wesen is in its being revealed, made visible. The essence of digital technology is not located in one particular set up but is in the act of bringing forth. How do versions relate?

The first thing to understand is that we have said that Wesen is going-on. In that sense these versions can not be taken as fixed arrangements they go on and have to stay in play. Revealing is the translation of Heidegger's term entbergen but as Weber points out translators are aware that the sense is actually harbouring forth where Bergen means to harbour or conceal and ent means forth or a change of place with respect to a former condition. Revealing then is understood as an act of bringing forth into security. However, Weber argues that there is an interesting contraction missed. Harbouring is certainly about securing, sureing up, and Weber points out it is talked of in terms of cherishing or protecting. However, harbouring forth, leaving shelter is an act of unsecuring "to venture into a certain insecurity." The mistake is to read Heidegger's central tenet as, for anything to go on it has to be secured. Weber translates entbergen as unsecuring. Ant assumes the first. It describes how versions or networks come together through translation but stops with security. The assumption is that everything acts in favour of the network at the point of security. This leaves us with three versions of digital technology all separate networks and no explanation for why these three might be brought together, why do these people need or choose to communicate? Weber tells us that the act of securing is answered by the act of unsecuring. He says: "technics starts out from a place that is determined by that which it seeks to exclude. Insecurity is its enabling limit". We can read this as recording since recording requires a degree of blankness or a lack of definition that is necessarily unsecured. We find this blankness or the under defined is described in Serres as noise or third man or parasite and as vital in communication and ordering. Serres (1982) talks about the thing to be communicated in its empirical situation that is content in a particular form. Since form varies from situation to situation, the logician is faced with teasing out the abstract notion or content from the noise of the many situations. Serres (1982) says:

"It is one and the same act to recognise an abstract being through the occurrences of its concrete, standardised form and to come to an agreement about this recognition, in other words, the act of eliminating cacography, the attempt to 
eliminate noise, is at the same time the condition of the apprehension of the abstract form and the condition of successful communication".

Serres goes on to explain that if it all was noise we couldn't differentiate anything from anything else "at the extreme limits of empiricism, meaning is totally plunged in to noise the space of communication is granular". The foot note says "Whence we see that if we admit the principle of undiscernables, the monads neither listen to nor understand each other. They are without doors or windows, an implication that Leibniz made coherent". ANT leaves us with a granular space with lots of disconnected monads, it fails to make their communication visible. The alternative is no noise, which, as Serres says, result in silence, no communication. Thus, a Monad's arranged world requires others as noise. The task is to maintain and design noise as noise designs the monad. To secure the abstract united world is the same act as writing the noise.

We have seen from Heidegger that the effects of unsecuring or revealing involves a covering of alternatives, with Benjamin we see that alternatives or past arrangements are required and present in the current arrangement. This also involves a covering or putting out of reach alternatives while being a product of alternatives. So unsecuring requires that we understand how monads come to arrange other monads as part of their own writing through excluding what shapes them. This involves understanding alternatives as noise to be fort against in these two ways.

We have already seen Billy's concern to describe her project by closing down alternatives, and writing her own activity on top where she said her photographs are not about movement, removement or replacement but are about taking photographs. In an example of unsecuring as opening to alternatives, John provides an example of how the designing of noise in the system is at the same time an unsecuring or a virtualisation, an enabling limit that affords a new set of arrangements or a new securing.

J: well (.) this last three weeks I can tell you l've been l've been really struggling with grey skies (.) and (.) I've been l've printed some grey squares out on the computer to see whether it was printing grey and they looked quite good (.) so I printed cut those off and I had an A4 sheet (.) short then (.) and I put a backing sheet on the back for it to slide down (.) but it never took the glossy one it took the one at the back (.) which was up side down (.) an old piece of paper that (.) l've got and its gone (.) and its printed me the best grey sky [l've ever seen (.) but its on the back] its

A:

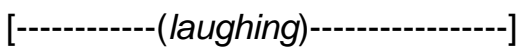

$\mathrm{J}$ : on the back of an ordinary sheet of Epsom paper (.) and its printed at the glossy setting (.) fourteen forty (.) and its superb (.) so don't throw away you're old sheets of paper just turn them over and you've got a smashing mat print

\section{U: don't don't tell Epsom that they'll be selling them as double sided paper}

Here we have presenting a mistake an accident that ends up producing the results he was seeking through a well-rehearsed set of procedures. He sets up the shape of the mistake in terms of the original set of procedures. We have backing sheets that are old sheets of paper in up side down with respect to the printer set up for best results. We have Epsom invoked and their concern for marketing quality. We also have John's project for a grey sky and his testing procedure. All this arrangement constitutes a settlement or a world organised to have a grey sky-printing machine that satisfies everyone concerned. Epsom supply instruction manuals for best results, users introduce a backing 
sheet, which organises old from new sheets. The world is organised, is secured, but as things are repeated (there is a procedural air to John's report) the shape of alternatives is made clearer. Backing sheets have the opportunity to slip wrong sides are arranged and worked up and given the opportunity in the current alignment to be printed. In terms of the first procedure old, and wrong, and upside down are as noise in the system. However, the system designs them as such. Every locking down and covering opens up and shapes alternatives - that is, every securing is answered by an unsecuring. Here we see the alternative actualised secured as the old settlement is secured a mistake occurs that spins off a new alignment of tech and people, practice and procedure. A marketing opportunity. A compossible bifurcation. This is the process of securing through movement or unsecuring.

\section{Society equals Multiplicity}

The community is required to maintain digital as a recording space where different configurations of its tradition and procedures can be shared. This secures also the society as virtual as with each monad arranged what constitutes the member ship, artists, technicians, and their history the darkroom are mobilised and organised as alternatives are closed down and new ones opened up. A new arrangement goes spinning out across the recording space that is digital society. The society requires a recordable surface to exist and joining is immersion into it and recording on to it.

Our last example comes from Billy's description of getting into digital photography and it is clear that she goes through different configurations of humans and nonhumans:

B: anyway when I decided I would buy a computer for photography I went to ti:ny I went to::: um oh all the other people that do these packages for you and then I went to: um pc wo::.rld and I got so confused with all all of the things that they have got there and I decided that (.) as I didn't know what I was doi::ng (.) I could have I could go to tiny and they would give me a camera and a a scanner and everything that I needed plus all these ga::mes and all sorts of things that I got free but I didn't want all of those things (.) s:::o in the end I decided l'd go to a little shop (.) in jubilee crescent (.) can't even remember the name of it (.) a::nd I went into the shop and I said to them look I know nothing about computers but what I want is really one for photography (.) I said I I and I really will need a computer I know but I want a scanner and a . erm (.) and a printer . and a camera because I didn't realise that I could do prints without having . just from an ordinary camera= that's how much I knew about it so I said look (.) I want to spend two thousand pounds (.) I want a good scanner (.) I want a good printer (.) I want a good computer (.) and I want a good camera (.) well the camera cost me five ninety nine (.) Which I needn't have bought but (.) I didn't realise that (.) knowing nothing (.) and having no one to ask so I said to them in the shop could you do what I want (.) so he said yes (.) so he fixed me up with everything I wanted (.) I left it entirely to him (.)

There is much we can comment on here but space denies us a comprehensive analysis. The key points to this discussion are discursive orderings that chart the move from the commercial certainty of what constitutes digital to the community who trade in multiple versions of digital technology maintaining it as an open recording space. Billy's story of getting into digital has her negotiating the packages on offer from the commercial world to the custom made package of the smaller trader. PC world, tiny computers and "all the other people that do these packages" present a background against which the uniqueness of the photographic society is charted. The story presents us with a large category of a large commercial sector, presenting consumers with set packages. Billy starts by 
negotiating the packages on offer from a position of ignorance, she says "I didn't know what I was looking for" and so she is injected into this economy of preorganised package. On the way, she finds extras that did not want: games, etc. In the end she opts for the smaller trader. She goes to a little shop, whose position in commercial terms is insignificant; she cannot remember the name, just its location.

The switch here is from Billy knowing nothing and being offered up solutions as packages to her controlling, demanding, and tailoring. The sense is that larger business presents non negotiable packages with little regard for individual needs that dictates the consumer space while the smaller trader presents nothing but responds with expert advise. Billy reports here that she knew nothing and had no one to ask, yet she uses clear and definite instruction to the trader, she was clear at the time presenting a four-part list of definite objects required for her to be into digital photography. This is interesting because in negotiating the acquisition of some kit Billy presents as someone with outcommunity, "having no one to ask", without knowledge, "knowing nothing", but she is clear on what she wants. Contrast this with the conversation on input devises, the discovery of different ways of doing things and the need to stake out her own project in terms of other projects. She goes from certainty about kit without community to a world of options and personal collections and preferences within community.

In addition, as we go through the immersion, kit is sidelined, games go then extra free bits, then the package notion for the tailored option. Significantly, the digital camera becomes an icon of what digital photography is not about. Notice that it is the fourth item in the list, given the closure that is achieved with three part lists the digital camera discursively sits outside the natural point of closure. It becomes a boundary object describing the move from commercial space to the photographic society. Billy injects her story with hind site on that issue and is picked up on for buying a digital camera in conversation over input devices.

The camera becomes the only clear marker that distinguishes the group from the commercial gatherings of the technology. The group is not presented as distinctly defined by their break with the commercial or in competition with the commercial, they are distinguished by the move to virtualisation of digital against the actualisation or gatherings of the commercial. The digital camera becomes a site where the centres of gravity are demonstrated as distinct. They are then distinguished by their gravity: process, versus central gathered. This is reflected in the experimental talk that permeates their presentations and conversations, they do not react to commerce but evolve through repetition and discovery. They carve out their own niche within the group and share stories. Histories come where projects intersect and where projects are distinct. Either way to be into digital is to develop through "trial and error" or going through your own "reams of paper" to gather together your own version and practice to write on to it to record on the social virtual space and spin out histories of what constitutes the technology and the society itself.

If digital photography were gathered once for all then we could take it or leave it. It requires the community to exist as a series of translations, of versions. As such the community offers a space to move through, the community is a site of movement and recording that in turn writes and rewrites the society. 


\section{Conclusions}

We started with the idea that the common sensical way to approach people and technology is to ask questions that seek to understand one category's activities within the other. How does society organise technology? We have argued that this form of inquiry is built on the notion that explanation rests on a representational and causal relationship between these categories - the goal is to uncover and understand the logical unity between them. This is seen in the need to find valid variables in the category that passively registers the activities of the active and distinct category. Latour argues that this requires us to jump the gap between a referee point and statements made about it, and argued that we should understand statements as part of what configures and performs or articulates the referent into being through movement through transformation and displacements into moments of individual substance. Benjamin's take on the symbolic parallels these ideas and locks them into an understanding of the monad. What became important was to understand how moment/monads or the actual are configured through movement, mass, and multiplicity.

Then, Heidegger has given us an understanding of how technologies come into being, into moments. Heidegger's work (understood through Weber) flags up the short falls of ANT as Heidegger requires us to understand the move of unsecuring through which every move of actualisation or organisation of a monad also requires movement and exposure to alternatives since it is itself constituted through alternatives as a multiplicity. Therefore, through the virtual we have a vocabulary that helps us understand stability through change. Unlike ANT, the virtual lets us in on the destructive movement of unsecuring that answers stability. ANT leaves us with a network, the collapse of which comes as a surprise (ANT and the other continent paper and Callon's scallops).

In terms of our data, we have seen how versions or monads are organised and how, since they are by nature multiple, new ones spin off. The virtual, unsecuring movement helps us notice the recording space is the mixture of the society and the technology and it is across this space that versions of both are written and rewritten.

Allegory underpins our new configuration of problematic complex, the virtual. The virtual can be thought of as the movement of transformation and displacement, the multiple existence of substance and as an enabling limit that secures, through movement, a recording space for solutions to be written onto, to secure the here and now. Since the virtual answers each securing with an unsecuring, we must look to explain stability as the management of alternatives. The essence of technology, of digital, is in configuring a world. The movement of technology into the home should now be read as the recording of a monad rather than the invasion of territory.

\section{References}

Bell, V. (1997). Falling into time: the historicity of the symbol. Other Voices. Vol .1, no. 1.

Benjamin, W. (1977). The origin of German tragic drama. Verso press.

Benjamin, W. (1969). "The work of art in the age of mechanical reproduction". In H. Ardent (ed.). Illuminations. Trans. by H. Zohn. New York: Schoken Books.

Callon, M. (1986). "Some Elements of a Sociology of Translation: Domestication of the Scallops and the Fishermen of Saint Brieuc Bay". In J. Law (ed.). Power, Action and Belief: a new 
Sociology of Knowledge? Sociological Review Monograph. London: Routledge and Kegan Paul. 32: 196-233.

Hamill, L. (2000). The introduction of new technologies into the household. Personal technologies. Vol. 4, 1-16.

Heidegger, M. (1977). "The question concerning technology". Trans. by A. Hofstadter. In D. F. Krell (ed.). Basic readings: Martin Heidegger. Revised edition. London: Routledge.

Hetherington, K. and Law, J. (Draft). "Allegory and interference: Representation in sociology". http://www.comp.lancaster.ac.uk/sociology/reskhjl1.html . Department of sociology, Lancaster University.

Latour, B. (1986). "The Powers of Association". In J. Law (ed.). Power, Action and Belief: a New Sociology of Knowledge? London, Boston and Henley, Routledge and Kegan Paul. 32: 264280.

Latour, B. (1999). Pandoras Hope: essays on the reality of science studies. Harvard University Press.

Law, J. (1992). "Notes on the Theory of the Actor-Network: Ordering, Strategy and Heterogeneity". Systems Practice 5: 379-393.

Leibniz, G. W. (1686). "Discourse on Metaphysics". In R. S. Woolhouse and R. Francks (eds.) (1998). G.W. Leibniz: Philospohical texts. Oxford.

Parker, J. (1997). The dialectics of allegoresis: Historical materialism in Benjamin's Illuminations. Other Voices. Vol. 1, no. 1.

Serres, M. (1968). "Le système de Liebniz et ses modèles mathématiques". In J. Crary (1991). Techniques of the observer. Cambridge, Massachusetts, London, England: MIT Press

Serres, M. (1982). "Platonic dialogue". In J. V. Harari and D. F. Bell (eds.). Hermes: Literature, Science, Philospohy. Baltimore and London: The John Hopkins University Press.

Weber, S. (1996). Mass Mediauras: Form, Technics, Media. Stanford University Press.

\section{Referencia}

Woodrow,J. (2002). The virtualisation of digital photography. Athenea Digital, 1. Disponible en http://antalya.uab.es/athenea/num1/Mwoodrow.pdf 